\title{
Mood as a Determinant of Attentional Focus
}

\author{
Constantino Sedikides \\ University of Wisconsin-Madison, U.S.A.
}

\begin{abstract}
Three experiments examined the effects of mood on self-focused versus external-focused attention. The results demonstrated that sad mood $\bullet$ (compared to neutral and happy mood) tends to induce self-focused attention, whereas happy mood (compared to sad mood) tends to elicit externalfocused attention. The effects of mood on attention were independent of the self-focusing nature of the mood-inducing event. A model is proposed to account for the relation between mood and self-focused attention. According to the model, sad mood produces momentary negative self-evaluation, which in turn creates uncertainty about one's self-worth. This instigates selfperception processes that result in heightened self-focused attention. In contrast, happy mood leads to certainty about one's self-worth, which allows an extroverted orientation.
\end{abstract}

\section{INTRODUCTION}

The construct of self-focused attention (defined as "an enhanced awareness of one's salient self-aspects"; see Carver, 1979, p. 1251) has had an eminent status in psychological theorising since the early 1970s. Selffocused attention has been shown to mediate self-regulation in a broad array of behavioural activities (for reviews, see: Carver \& Scheier, 1981; Duval \& Wicklund, 1972; Scheier \& Carver, 1988). further, self-focused attention has been established as a concomitant of various clinical disorders (Ingram, 1990), including depression.

Requests for reprints should be sent to Constantine Sedikides, Department of Psychology, University of Wisconsin-Madison, 1202 West Johnson Street, Madison, Wl 53706, U.S.A.

I thank J. Mark G. Williams and two anonymous reviewers for their perceptive comments on an earlier draft of this manuscript. I also acknowledge the assistance with data collection and coding of Kirstin Carlson, Jodie Rapkin, Joy Russel, and Heather Zousmer. Part of this research was supported by a small grant from the University of Wisconsin Psychology Department. 
Depression has been found to be associated with a heightened level of self-focused attention by a variety of studies using diverse methodologies and measurement procedures and using both clinical and subclinical samples of depressives (e.g. Ingram, Lumry, Cruet, \& Sieber, 1987; Ingram \& Smith, 1984; Larsen \& Cowan, 1988; Pyszczynski \& Greenberg, 1985,1986; Smith \& Greenberg, 1981; Smith, Ingram, \& Roth, 1985). The strong presence of self-focused attention in depression has recently led researchers to begin re-examining the determinants of self-focused attention (Wood, Saltzberg, \& Goldsamt, 1990).

In the laboratory, self-focused attention has been induced by presenting subjects with stimuli that are reminders of the self, such as voice recordings, cameras, and mirrors'(Carver \& Scheier, 1981). Other self-focused attention inducers include audience presence, eye contact, and bodily activity (e.g. Carver \& Scheier, 1978; Fenigstein \& Carver, 1978; Wegner $\&$ Giuliano, 1980). Despite the success of the above procedures in eliciting self-focused attention, these procedures can not explain why self-focused attention is higher among depressives than among normals. There must exist naturalistic inducers of self-focused attention, which serve as correlates of depressive but not normal states (cf. Wood et al., 1990). One prominent correlate of depression is șad mood. Hence, sad mood might qualify as an induccr of self-focused attention.

Mood (defined as "a general and pervasive feeling state that is not directed toward a specific target"; see Wood et al., 1990, p. 900.) and selffocused attention have indeed been found to be negatively correlated in both a Meld study (Csikszentmihalyi \& Figurski, 1982) and a laboratory study (Sedikides, 1990). Specifically, Csikszentmihalyi and Figurski (1982) found self-focused attention to be associated with more negative affect when subjects were engaged in voluntary activities. In a laboratory study, Sedikides (1990) obtained a negative correlation between self-focused attention and mood, $\mathrm{r}(98)=-10.348, P<0.0001$. Self-focused attention was assessed by the Private Self-Consciousness subscale of the SelfConsciousness scale (Fenigstein, Scheier, \& Buss, 1975), and mood was measured through the 8-point single-item scale "In general, how do you feel most of the time?", with 1 labelled "very sad" and 8 labelled "very happy".

\section{Does Mood Affect Self-Focused Attention?}

Two theoretical views offer guidance to the question whether and how mood affects self-focused attention. Salovey and Rodin (1985) proposed that mood states shift attention inward. People become preoccupied with discovering the source of their mood, because mood is a distinctive and surprising state. People begin their search for the causes of their mood by 
focusing on internal rather than external cues. One important postulate of Salovey and Rodin's (1985) theoretical view is that both sad and happy mood can lead to self-focused attention.

On the contrary, Cunningham and his colleagues (Cunningham, 1988a,b; Cunningham, Steinberg, \& Grev, 1980) suggested that sad and happy mood produce disparate results on a variety of cognitive and behavioural measures. Sad mood involves an avoidant and egocentric orientation; it elicits a problem-focused, ruminative, and self-reflective mode. Thus, sad mood should-lead to self-focused attention. On the other hand, happy mood involves a social, approach, and expansive orientation. Happy mood is likely to increase the chances of engagement in social interaction and self-disclosure. Consequently, happy mood should produce external-focused attention.

Two recent experiments by Wood et al.(1990) yielded results consistent with the view held by Cunningham and his colleagues. Mood was induced via either an imagery procedure (Experiment 1) or music (Experiment 2). Self-focus was measured through either a fill-in-the-blank-with-a-pronoun task (Experiment 1) or free-response thought samples and the Private SelfConsciousness (PSC) scale (Experiment 2). Sad subjects were found to be higher in self-focused attention than neutral mood subjects -(Experiments 1 and 2) and happy subjects (Experiment 2). Sad mood induced selffocused attention, but neutral or happy mood did not. In fact, happy mood was found to be negatively correlated with self-focused attention.

The present research has three objectives. First, the research purports to partially replicate Wood et al.'s (1990) findings by using different mood induction procedures and self-focused attention measures. Secondly, the research* aims at expanding Wood et al.'s (1990) findings, by further exploring the effects of happy mood on attention. As noted above, Salovey and Rodin's (1985) and Cunningham et al.'s <1980) models make contradictory predictions. Salovey and Rodin propose that happy mood should lead to heightened self-focused attention, whereas Cunningham et al. posit that happy mood should lead to heightened external-focused attention. The final goal of this article is to propose a tentative model felating mood and self-focused attention.

\section{EXPERIMENT 1}

This experiment examined the effects of sad, neutral, and happy mood on self-focused attention. In manipulating mood, the following criteria were met. First, subjects were instructed to imagine an experimenter-provided sad, neutral, or happy mood-inducing event rather than generate their own idiosyncratic events (as did subjects in Wood et al., 1990). Secondly, the referent of the mood-inducing event was kept constant across the mood 
conditions. That is, all subjects imagined an event referring to themselves. Both criteria were employed in order to control for possible differences in mood intensity among subjects. Such differences are likely to be introduced by subjects* diversified personal experiences.

In assessing self-focused attention, the following concerns were taken into consideration. The construct of self-focused attention was assessed not by the existing form of the PSC scale (as in Wood et a!., 1990, experiment 2 ), which measures chronic self-focused attention, but rather by a modified form of the PSC designed to reflect momentary $\bullet$ shifts in self-focused attention. Additionally, an attempt for convergence in the measurement of the construct was made. Thus, a procedure that has been used to induce self-focused attention (Fenigstein \& Levine, 1984) was slightly modified for the purpose of detecting self-focused attention.

\section{METHOD}

\section{Subjects}

Subjects were 30 male and 30 female University of Wisconsin (UW) undergraduates enrolled in introductory psychology courses. Male and female subjects were equally represented in each experimental condition. Subjects were randomly assigned to the conditions of the experiment. Subjects were run in groups of 3 to 8 . Partitions set in the experimental room prohibited subjects from seeing one another when seated.

\section{Procedure}

Each subject was assigned to either a sad, neutral, or happy mood condition. Mood was induced through a guided imagery task (Dermer, Cohen, Jacobsen, \& Anderson, 1979; Wright \& Mischel, 1982). Subjects in the sad mood condition were asked to imagine for $2 \mathrm{~min}$ that they were burned in a fire and were seriously disfigured. Subjects were shown photographs of burn victims to assist them in their imagination. Subjects were subsequently allotted $3 \mathrm{~min}$ to write about the event. Subjects in the neutral mood condition imagined themselves drawing a map of the United States for $2 \mathrm{~min}$, and were given sample drawings of the continent of North America and various states to assist them in their imagination. Subjects subsequently spent $3 \mathrm{~min}$ drawing a map of the United States. Finally, subjects in the happy mood condition imagined themselves winning a free cruise in the Caribbean islands, and were given Windjammer travel brochures to help them imagine themselves in the trip. Then, subjects spent 3 min writing about the event. 
After the mood induction procedure, subjects filled out a mood manipulation check. They responded to the question "How are you feeling right now?" on an 1 (Extremely sad) to 8 (Extremely happy) scale. Next, subjects completed the following two measures in counterbalanced order. They filled out a version of the PSC scale that was adapted to measure momentary rather than dispositional self-focused attention. For example, items were modified from "I'm generally attentive to my inner feelings" and "I sometimes have the feeling that I'm off somewhere watching myself to "I'm right now attentive to my inner feelings" and "I right now have the feeling the I'm off somewhere watching myself*. The scale was also altered by expanding the original 4-point scale (i.e. Fenigstein et al., 1975) to a 9-point scale, in order to increase the scale's sensitivity to detect potentially weak effects. The modified PSC scale appears in the Appendix. High scores indicate high self-focused attention. (Items 2 and 5 are reversed scored.)

Subjects were also asked to tell a story. The specific instructions (modelled after Fenigstein \& Levine, 1984) were as follows: "We would like you to construct a story. The story should describe an event, its antecedents and outcomes, and the thoughts and feelings of persons taking part in the event. The central character of the story can be you or someone else." Subjects were given 10min to think about and write the story. Choice of the self as referent of the story was assumed to be an indication of high self-focused attention.

\section{Results}

Sex of subjects and the counterbalancing factor did not yield any significant results. Thus, effects involving these factors are not reported.

\section{Manipulation Check}

An analysis of variance (ANOVA) on subjects* ratings of their own mood attested to the effectiveness of the mood induction techniques, Mood Valence main effect $\mathrm{F}(2,48)=11.13, P<0.0001$. Orthogonal contrasts $(P<0.01)$ revealed that sad mood subjects $\left(\begin{array}{ll}M & 3.80) \text { felt }\end{array}\right.$ sadder than neutral mood subjects $(M=4.90)$, which in turn felt less happy than happy mood subjects $(\mathrm{M}=6.05)$.

\section{Self-focused Attention}

Modified PSC Scale. The scale responses were internally consistent $($ alpha $=0.84)$. An ANOVA on subjects* scores on the PSC scale yielded a significant Mood Valence main effect, $F(2,48)=6.64, P<0.003$. 
TABLE 1

Number of Subjects who Preferred to Write a Story about Themselves vs. Someone Else in Experiment 1

\begin{tabular}{lccc}
\hline & $\begin{array}{c}\text { Sad Mood } \\
\text { Subjects }\end{array}$ & $\begin{array}{c}\text { Neutral Mood } \\
\text { Subjects }\end{array}$ & $\begin{array}{c}\text { Happy Mood } \\
\text { Subjects }\end{array}$ \\
\hline Self & 9 & 5 & 10 \\
Other & 11 & 15 & 10 \\
\hline
\end{tabular}

Orthogonal contrasts $(\mathrm{P}<0.01)$ revealed that sad mood subjects $(\mathrm{M}=$ 6.79) reported being higher in momentary private self-consciousness than either neutral mood subjects $\{M=5.90)$ or happy mood subjects $(M=$ 6.14). The last two groups did not significantly differ from one another in reported momentary private self-consciousness $(\mathrm{P}<0.36)$.

Story. The number of times the central referent of the story was the self versus another person was entered into a log-linear chi-square analysis. Overall, subjects demonstrated a weak tendency to write stories about another person $(\mathrm{n}=36)$ than the self $(\mathrm{n}=24)$, chi-square $($ d.f. $=1)=$ 2.52, $P<0.11$. The crucial interaction between Mood Valence and Story Referent was not significant, chi-square $($ d.f. $=2)=2.82, P<0.24$ (Table 1). Sad mood (as opposed to neutral or happy mood) did not lead subjects to tend to write stories about themselves.

\section{Discussion}

Experiment 1 demonstrated that sad mood, but not happy mood, can induce self-focused attention, as manifested by the modified PSC scale results. Experiment 1 replicated findings obtained by Wood et al. (1990, Experiment 2) using a different mood induction technique and a different self-focused attention assessment task (i.e. the modified PSC scale) than did Wood et al. The results are consistent with the implications of the theoretical position taken by Cunningham and his colleagues regarding mood effects, namely that sad and happy moods do not bear similar.effects on self-focused attention.

However, the story measure reflected null effects of mood on selffocused attention. This measure may not be a sensitive index of selffocused attention. People may implicitly assume that stories are typically told about others rather than the self, and this assumption may interact with mood effects. A second possibility for the null results of the story measure is that the results are simply due to sampling error. 


\section{EXPERIMENT 2}

Experiment 2 introduced several new features designed to remedy possible weakness of Experiment 1. First, in Experiment 2, the story measure was revised. Specifically, subjects were simultaneously presented with selfreferent and other-referent pronouns, and were given the option to write a story about either the self or someone else. This option should-somewhat counter the hypothesised effects of subjects* expectation of writing a story about someone else rather than the self, as both potential referents of the story were made equally accessible in subjects' minds. Further, this replication should reduce the chances of a sampling error.

Moreover, Experiment 2 used a third measure of self-focused attention, a thought-listing task. Subjects were asked, after the mood induction procedure, to write down freely any thoughts that currently crossed their minds. The thought-listing task would allow for a potential replication of the findings of Experiment 1 and for additional convergence in the measurement of self-focused attention. Most importantly, the thoughtlisting task would allow for an examination of the effects of mood on external-focused attention, as subjects* thoughts could be subdivided into self-focused and external-focused ones.

In Experiment 1, care was taken to keep the referent of the moodinducing event constant. The referent in all events was the self. However, a particular mood-inducing event may lead to higher self-focused attention not because of its affective quality, but because of complex interactions between the content of the event itself and aspects of the self-concept. For example, the sad event used may implicate different parts of the selfconcept "(and thus be more self-focusing per se) than either the neutral or happy event. Experiment 2 attempted to control -for the above possibility in two ways. First, a friend was designated as the event referent rather than the self. Secondly, an additional mood-inducing event was implemented.

\section{Method}

\section{Subjects}

A total of 32 female and 31 male UW undergraduates participated in the experiment for extra introductory psychology course credit. An approximately equal number of female and male subjects were represented in each experimental 'condition. Subjects were randomly assigned to the experimental conditions, and were run in-groupsof 2 to 8. Dividers in the experimental room obstructed visual contact among subjects. 


\section{Procedure}

Subjects were put into a sad, neutral or happy mood, using a procedure similar to that of Experiment 1. However, the referent of the moodinducing event was a friend rather than the self. Furthermore, subjects in the sad mood condition were additionally asked to imagine that their friend had died; subjects in the neutral mood condition were asked to imagine that their friend was riding a bus; and subjects in the happy mood condition were asked to imagine that their friend had just won $\$ 1,000,000$ in the Wisconsin Lottery.

After going through a mood manipulation check, subjects completed three dependent measures in counterbalanced order. First, subjects filled out the revised form of the PSC scale. Secondly, subjects completed a thought-listing task (Cacioppo \& Petty, 1981). Specifically, they were instructed to "write any and all thoughts that are going through your mind right now". Subjects were provided with a quarter-page booklet and were instructed to write only one thought per page without turning to previous pages. Note that Wood et al. (1990, experiment 2) used a similar procedure to assess "thought-samples", but these investigators did not require that subjects write down one thought per page. Instead, it appears from Wood et al.'s description that subjects wrote down all their thoughts on the same page. As a consequence, subjects' thoughts were likely to have been guided by a great deal of their previously listed thoughts. The advantages of having subjects list their thoughts on separate pages are that: (1) subjects are only influenced by a relatively small sample of their previously listed thoughts; and (2) this process simulates the naturalistic conversational flow of thought production.

Finally, subjects were provided with two lists of 20 words each. The two lists were on the same page. The order of the lists on the page was counterbalanced. The first list contained five self-referent pronouns, and the second list contained live. other-referent pronouns. Subjects were instructed to choose one list and then construct a story using as many words from that list as possible. Subjects were presented with an opposite sex other-referent word list.

\section{Results}

Sex of subjects and the counterbalancing factor produced no significant results. Effects involving these two factors are not reported below.

\section{ManipulationCheck}

An ANOVA on subjects* ratings of their own mood demonstrated that the manipulations were effective, Mood Valence main effect $F(2,45)=$ 65.17, $P<0.0001$. Orthogonal contrasts $\{P<0.0001)$ revealed that sad 
mood subjects $(\mathrm{P}=3.43)$ felt sadder than neutral mood subjects $(M=$ 4.71), who in turn felt less happy than happy mood subjects $(M=6.43)$.

\section{Self-focusedAttention}

Modified PSC Scale. Responses to the scale were internally consistent $($ alpha $=0.88)$. Mood Valence affected the degr-cc of momentary private self-consciousness, $\mathrm{F}(2,45)=5.31, P<0.008$. Orthogonal contrasts ${ }^{\wedge}<$ $0.002)$ revealed that sad mood subjects $(M=7.02)$ became more privately self-conscious than either neutral mood subjects $(\mathrm{M}=5.69)$ or happy mood subjects $(M=5.48)$. The last two groups did not significantly differ from one another $(\mathrm{P}<0.66)$. These results replicate corresponding findings of Experiment 1.

Thought-listing Task. Two independent judges coded subjects' thoughts as self-focused (when the subject of the clause was the self), externalfocused (when the subject of the clause was either someone else or an inanimate object), or mixed (when the subject of the clause included the self and someone else) (Greenberg \& Pyszczyski, 1986; Wood et al., 1990, experiment 2). Only $4 \%$ of subjects' thoughts were coded as mixed. Thus, this category was omitted from further analyses. The coders agreed on $98 \%$ of the cases and resolved disagreement through discussion. Note that Wood et al. \{1990, p. 903) reported validation data for the thought-listing measure. In a laboratory experiment, they found that the presence of a mirror evoked a higher percentage of self-focused thoughts than externalfocused thoughts.

Ratios 'were subsequently computed for the sell-focused and -externalfocused thoughts for each mood condition. The ratio of self-focused thoughts was computed by dividing up for each subject the number of selffocused thoughts by the total number of thoughts-\{self-focused, externalfocused, and mixed). A similar procedure was used to compute the ratio of external-focused thoughts. These ratios were then entered in separate ANOVAs.

The ANOVA conducted on the ratio of self-focused thoughts yielded a significant Mood Valence main effect, $\mathrm{F}(2,45)=11.43, P<0.0001$. Orthogonal contrasts $(P<0.002)$ revealed that sad mood subjects $\{h i=$ $0.50)$ listed more self-relevant thoughts than either neutral mood subjects $(\mathrm{M}=0.29)$ or happy mood subjects $(M=0.21)$. The last two groups did not significantly differ from one another $P<0.18$ ). These results replicate Wood et al. (1990, experiment 2).

The ANOVA performed on the ratio of external-focused thoughts produced a marginally significant Mood Valence main effect, $F\{2,45)=$ 2.55, $P<0.09$. Orthogonal contrasts revealed that happy mood $(\mathrm{M}=$ $0.44)$ produced more external-focused thoughts than $\operatorname{sad} \operatorname{mood}(\mathrm{M}=\boldsymbol{(} \boldsymbol{M}=$ 
$0.23), P<0.03$, but not neutral mood $(\mathrm{M}=0.33), P<0.29$. The last two groups did not significantly differ from one another, $P<0.27$. These results differ from Wood et al.'s (1990, experiment 2) results, which indicated that happy and sad subjects generated an approximately equal number of external-focused thoughts.

Because subjects' references to their feelings were coded as self-focused thoughts, the above self-focused ratios were determined by both subjects* references to themselves and to their feelings (Greenberg \& Pyszczynski, 1986). Stated otherwise, the self-focused ratios reflect, in part, subjects* mood and not just their self-focused attention state. A possibility exists that a given mood state (e.g. sad mood) contributed more to subjects' selffocused thoughts than other moods.

To control for this possibility, self-focused thoughts were coded into mood-related thoughts (when subjects made reference to their mood) and moodless thoughts (when subjects did not refer to their mood), after Wood et al. (1990, experiment 2). Moodless ratios were then computed for each mood condition. The ratios were subsequently entered into an ANOVA.

The ANOVA resulted in a significant Mood Valence main effect, $\mathrm{F}(2,45)=8.41, P<0.001$. Orthogonal contrasts $(\mathrm{P}<0.002)$ revealed that sad mood subjects $(\mathrm{M}=0.53)$ listed more self-referent thoughts than either neutral mood subjects $(M=0.28)$ or happy mood subjects $(\mathrm{M}=0.19)$. The last two groups did not significantly differ from one another $(P<0.26)$. The results based on the analysis of moodless thoughts replicate the corresponding results of self-focused ratios, as well as the results of Wood et al. (1990, experiment 2). Mood Valence did not interact with quality of self-focused thoughts.

Story. A log-linear chi-square analysis revealed that when the self as story referent is made equally accessible in memory to another person, subjects prefer to write a story about the self, chi-square $($ d.f. $=1)=$ 17.40, $P<0.00001$. The crucial interaction between Mood Valence and Referent was not reliable, chi-square $($ d.f. $=2)=2.42, P<0.30$. Sad

TABLE 2

Number of Subjects who Preferred to Write a Story about Themselves vs. Someone Else in Experiment 2

\begin{tabular}{lccc}
\hline & $\begin{array}{c}\text { Sad Mood } \\
\text { Subjects }\end{array}$ & $\begin{array}{c}\text { Neutral Mood } \\
\text { Subjects }\end{array}$ & $\begin{array}{c}\text { Happy Mood } \\
\text { Subjects }\end{array}$ \\
\hline Self & 16 & 19 & 15 \\
Other & 5 & 2 & 6 \\
\hline
\end{tabular}


mood (as opposed to neutral or happy mood) did not affect subjects' preferences of writing a story about themselves(Table 2).

\section{Discussion}

Sad mood (in comparison to neutral and happy moods) induced high selffocused attention, as assessed by both the modified PSC scale and the thought-listing task. Experiment 2 replicated the-current Experiment 1 as well as Wood et al.'s results. Moreover, experiment 2 extended Wood et al.'s findings by (at least tentatively) demonstrating that a happy mood can induce more external-focused thoughts than a sad mood, a finding that is new to the literature. The results of Experiment 2 were generally consistent with the view espoused by Cunningham and his colleagues, according to which sad mood is likely to elicit self-focused attention whereas happy mood is likely to evoke external-focused attention.

The new version of the story measure was shown to be insensitive to capturing the self-focused attention state. It is not quite-clear why the story measure was ineffective. Certainly, subjects* assumed preference to tell stories about others rather than themselves was countered by the simultaneous presentation of self-referent and other-referent pronouns. In fact, subjects manifested a strong preference for making the self the protagonist of their stories. Further, the possibility of a sampling error was reduced by conducting the second experiment. In any event, based on the results of Experiments 1 and 2, it is suggested that the story measure is abandoned in future research on the effects of mood states on self-focused attention.

\section{EXPERIMENT 3}

The reported research lent support to the notion that the effects of mood on attention are bi-directional: "Sad mood (in comparison to neutral and happy moods) tends to draw attention inward, whereas happy $\operatorname{mood}^{\wedge}$ in comparison to sad mood) tends to direct attention outward. However, a critical issue still remains unresolved. To what extent were the mood induction procedures confounded with attentional focus? How likely is it that the imagery tasks varied in the amount of self-focused attention they induced, independently of mood?

There are reasons to believe that the effects of imaging on self-focused attention were constant across the three mood conditions, and thus inconsequential. The instructions given to subjects as a part of the mood induction technique in Experiment 1 consistently (i.e. throughout the three mood conditions) asked them to -put the self at the centre of the felt experience and think through the implications of the event for the-self. Further, subjects in Experiment 2 were consistently asked to think about 
the implications of the mood-inducing events for a friend of theirs, a task that is likely to be less self-focusing than thinking about the self.

However, the sad imaging differed from the neutral and happy imaging on the dimension of body-centredness. A body-centred event appears to be inherently more concrete, absorbing and self-focusing than a non-bodycentred event- As far as Experiment 1 is concerned, people might have tended to focus on themselves more when imagining themselves being seriously burned and disfigured (a body-centred experience) than when imagining themselves drawing a map or going on a" cruise (a non-bodycentred activity). In the last two cases, attention was likely focused on "external" objects, such as the map, the states, the boat, and the weather. The same might be true in Experiment 2. Imagining the death of a friend (again, a body-centred experience) may be inherently more self-focusing than riding a bus or winning the lottery (which represent non-body-centred activities). Consequently, the constancy across the three mood conditions of the instructions to put the self (Experiment 1) or a friend (Experiment 2) at the centre of attention might not have overcome the potential differences in the images. If the images started from different baselines of self-focused attention, consistent instructions may enhanced self-focus or external-focus effects, but not altered the relative standing of each image to the other.

To tackle this problem, Experiment 3 manipulated the degree of imaging body-centredness. Half of the subjects were asked to imagine body-centred events, whereas the remaining half of the subjects were requested to imagine non-body-centred events.

\section{Method}

\section{Subjects}

$A$ total of $60 \mathrm{UW}$ undergraduates (53 women and 7 men) participated as subjects and each received a $\$ 4$ payment. Subjects were randomly assigned to the experimental conditions, and were run in groups of 3 to 6 . Subjects sat in partitioned slots in the experimental room.

\section{Procedure}

Subjects in the body-centred condition were put into an either: 41) sad mood by imagining that they suffered from facial and bodily disfigurement in a fire; (2) neutral mood by mentally going through their bodily parts one by one; or (3) happy mood by imagining that their hair were done really well by a skilled hairdresser and they wore a nice outfit. 
Subjects in the non-body-centred condition were placed into an either: (1) sad mood by imagining that a much desired holiday cruise to the Caribbean islands was cancelled the last minute; \{2) neutral mood by imagining that they were riding a bus; or £3) happy mood by imagining that they won a free holiday cruise to the Caribbean islands.

Subjects were allotted $2 \mathrm{~min}$ to complete the imagery task. Then, they were given an additional $3 \mathrm{~min}$ to write about their imagined experiences. The instructions of the latter task emphasised the body-centredness dimension of the task. Subjects in the"body-centred condition were encouraged to write about themselves (e.g. how their face or body would look like), whereas subjects in the non-body centred condition were invited to write about external targets (e.g. the new places they would see or fail to see, or the bus).

Next, subjects rated their mood on three 9-point bipolar scales, anchored with sad-happy, depressed-elated, and gloomy-contented. Finally, subjects completed the revised form of the PSC scale and a thought-listing task in counterbalanced order.

\section{Results}

The counterbalancing factor yielded no significant results, and effects associated with this factor are not reported below.

\section{Manipulation Check}

The three mood scales were highly intereorrelated (rs 0.70 to 0.83 , Ps $<0.0001)$ and internally consistent (alpha $=0.78)$. The mean of the three scales was entered into an ANOVA. The mood manipulations were effective, Mood Valence main effect $\mathrm{F}(2,54)=64.97, P<0.0001$. Orthogonal contrasts $(P<0.01)$ revealed that sad mood subjects $-(\mathrm{M}=$ 4.27) felt sadder than neutral mood subjectsj(Af $\ll=5: 45)$, who in turn felt less happy than happy mood subjects $(\mathrm{M}=6.40)$. Mood Valence did not interact with Body-Centredness, $F(2,54)-0.11, P<0.90$.

\section{Self-focused Attention}

Modified PSC Scale. Subjects' responses to the scale were internally consistent (alpha $=0.86)$. Mood Valence influenced the degree of momentary private self-consciousness, $\mathrm{F}(2,54)=10.68, \mathrm{P}<0 .-0001$. Orthogonal contrasts $(P<0.001)$ indicated that sad mood subjects $(\mathrm{M}=6.60)$ became more privately self-conscious than either neutral mood subJ€cts $(\mathrm{M}=5.35)$ or happy mood subjects $(M=5.50)$. The last two groups did not significantly differ from one another $(P<0.71)$. The interaction between Mood 
Valence and Body-Centrcdncss was not significant, $\mathrm{F}(1,54)=0.71, P<$ 0.50 . These results fully replicate findings of Experiments 1 and 2 .

Thought-listing Task. Two judges independently coded subjects' thoughts as self-focused, external-focused, or mixed. The last category was omitted from the analyses, because only $7 \%$ of the thoughts were coded as mixed. Intercoder agreement was $93 \%$. Coders settled disagreements via discussion.

The ANOVA performed on the ratio of self-focused thoughts produced a significant Mood Valence main effect, $\mathrm{F}(2,54)=6.84, P<0.002$. Orthogonal contrasts $(\mathrm{P}<0.01)$ revealed that sad mood subjects $M=$ 0.52) listed more self-relevant thoughts than either neutral mood subjects $(M=0.27)$ or happy mood subjects $(\mathrm{A} /=0.33)$. The last two groups did not significantly differ from one another $(\mathrm{P}<0.24)$. The interaction between Mood Valence and Body-Centredness failed to reach significance, $\mathrm{F}(2,54)=1.66, P<0.20$. These results replicate corresponding findings of Experiment 2.

The ANOVA conducted on the ratio of external-focused thoughts yielded a significant Mood Valence main effect, $\mathrm{F}(2,54)=3.75, P<0.03$. Orthogonal contrasts showed that happy mood $(M=0.47)$ elicited more external-focused thoughts than sad mood $(M=0.27), P<0.05$, but not neutral $\operatorname{mood}(\mathrm{M}=0.43), P<0.88$. The difference between the last two groups was marginally significant, $P<0.08$. Mood Valence did not interact with Body-Centredness, $\mathrm{F}(2,54), P<0.93$. These results are consistent with the relevant findings of Experiment 2.

Finally, an ANOVA on the moodless ratios yielded a significant Mood Valence main effect, $\mathrm{F}(2,54)=3.46, P<0.04$. Orthogonal contrasts $(P<0.06)$ revealed that sad mood subjects $\{M=0.39)$ listed more selfreferent thoughts than either neutral mood subjects $(M=0.21)$ or happy mood subjects $(\mathrm{M}=0.25)$. The last two groups did not significantly differ from one another $(P<0.79)$. Again, Mood Valence did not interact with Body-Centredness, $\mathrm{F}(2,54)=0.93, P<0.40$.

\section{Discussion}

The absence of a significant interaction between Mood and BodyCentredness in Experiment 3 reinforced the notion that the effects of mood ori attention are independent of the self-focusing nature of the moodinducing event.

Subjects in the body-centred condition reported being slightly more selffocused than subjects in the non-body-centred condition, with regard to both the modified PSC scale and the thought-listing task. However, these trends were only directional. The corresponding body-centredness main 
effects were not significant. It appeared that the body-centredness manipulation per se was not sufficient to produce reliably high self-focus. Diverting attention to the bodily self versus social self, elicited comparable degrees of self-focused attention.

\section{GENERAL DISCUSSION}

Two theoretical perspectives make divergent predictions regarding mood effects on self-focused attention: Salovey and Rodin (1985) maintain that both sad and happy moods are potential inducers of self-focused attention. In contrast, Cunningham and his colleagues (Cunningham, 1988a,b; Cunningham et al., 1980) suggest that sad mood is likely to induce self-focused attention, whereas happy mood is likely to induce external-focused attention. The results of three experiments were generally consistent with the view held by Cunningham and his colleagues.

The reported set of experiments convincingly demonstrates that the effects of mood on attention are due to mood valence per se rather than the differential attention focusing effects of the three mood valences: Sad mood (in comparison to neutral and happy moods) tends to elicit selffocused attention, and happy mood (in comparison to sad mood) tends to invoke external-focused attention, irrespective of degree of bodycentredness of the imagery tasks.

\section{Attentional Effects of Happy and Neutral Mood}

The effects of happy mood were indistinguishable from the effects of neutral mood, despite the manipulation checks showing that subjects in the happy mood condition reported being happier than subjects in the neutral mood condition. The reasons for this are not clear. One possibility is that the effects of happy mood (compared to the effects of sad mood) are short-lived, and subjects quickly relapse to a neutral mood state, which is naturally a slightly affectively pleasant state. Future research should address this possibility. In any event, the obtained results are consistent with theoretical and empirical work pointing to asymmetrical effects of happy and sad mood (e.g.Clark \& Isen, 1982; Taylor, 1991; Wood et al., 1990).

\section{A Model Relating Mood and Self-focused Attention}

How can the effects of mood on self-focused attention be explained? One could argue that the increased self-focused attention that mood elicits may be due to the unexpected and distinctive nature of affective states (Salovey 
\& Rodin, 1985; Wegner \& Giuliano, 1980). Affective states may cause disruptions in regular functioning and thus promote self-regulatory activity, which in turn induces self-focused attention (Pyszczynski \& Greenberg, 1987). However, this explanation cannot account for the discrepant effects of sad and happy mood. That is, happy mood can be equally surprising and disruptive of normal functioning as sad mood. Certainly, in the context of the present experimental tasks there is no reason to believe that the induced sad mood states were more surprising and disruptive than the induced happy mood states.

The discrepant effects of sad and happy mood on self-focused attention can be reconciled by acknowledging the mediational role of self-perception (Salovey \& Rodin, 1985). Mood states affect the way we perceive ourselves. Specifically, mood affects: (1) the amount of time we attend to selfrelevant information; (2) the free recall, recognition memory, and retrieval latencies of self-relevant information; "(3) the valence of judgements referring to the self; and (4) the valence of expectancies about future behaviour involving the self. Mood effects on self-perception are congruent with mood valence. That is, in comparison with happy mood subjects, sad mood subjects tend to attend longer and remember better unfavourable rather than favourable self-relevant information, tend to make more unfavourable judgements of themselves, and tend to express lower success expectancies for future tasks (see Sedikides, in press, for a review).

Uad mood, then, leads to negative self-perception and self-evaluation. Negativity in self-perception and evaluation creates a state of uncertainty about one's worth (Baumgardner, 1990; Baumgardner, Kaufman, \& Levy, 1989; Campbell, 1990; Snyder \& Clair, 1977; Swann, 1985). This state of uncertainty is likely to be accompanied by weak or ambiguous internal cues, a condition that enhances the probability of instigation of selfperception processes (Bern, 1972) and, hence, a heightened level of selffocused attention. The model is schematically represented in Fig. 1.

In contrast, happy mood is likely to lead to positive self-evaluation (Sedikides, in press) and, thus, to increased certainty regarding one's selfworth. Certainty is likely to be associated with strong and unambiguous internal cues and, thus, to divert attention from the self and direct it to external cues. As a result, happy subjects will become external-focused. (See Fig. 1.)

The effects of happy mood in the present investigation paralleled the effects of neutral mood. This has implications for the proposed model. Assuming that neutral mood essentially involves a slightly positive state, neutral mood might exert attentional effects through the same mechanisms as happy mood does (see preceding paragraph). Alternatively, it is plausible that both happy and neutral moods promote the maintenance of the existing attentional focus, which is likely to be external. This claim is 
SAD MOOD

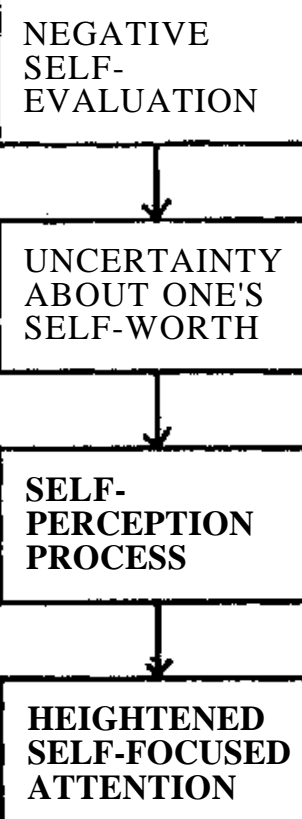

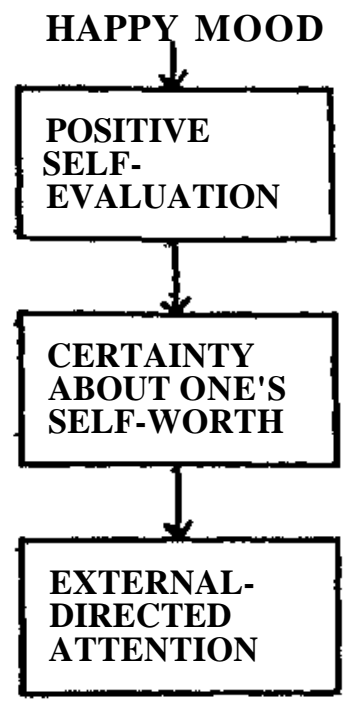

FIG. 1. A model relating mood and self-focused attention.

consistent with the proposal that a happy mood reinforces the pursuit of already established goals (Oatley \& Johnson-Laird, 1987, p. 36).

Certainly, aspects of the model need to be empirically verified. For example, research will need to provide convincing evidence that uncertainty about one's self-worth leads to weak and ambiguous internal cues, whereas certainty is accompanied by strong and unambiguous internal cues. Nevertheless, the model takes a necessary first step towards understanding the divergent effects of sad and happy mood on attention. Additionally, the model is consistent with findings that link sad mood at encoding with increased recall of self-referent information (Brown \& Taylor, 1986) and with findings that link aversive events with selfreflective, avoidant behaviour particularly, under self-focused attention conditions (Archer, Hormuth, \& Berg, 1982; Thompson, Cowan, \& Rosenhan, 1980). 


\section{REFERENCES}

Archer, R.L., Hormuth, S.E., \& Berg, J.H. (1982). Avoidance of self-disclosure: An experiment under conditions of self-awareness. Personality and Social Psychology Bulletin, 8, 122-128.

Baumgardncr, A.H. (1990). To know oneself is to like oneself: Self-certainty and self-affect. Journal of Personality and Social Psychology, 58, 1062-1072.

Baumgardner, A.H., Kaufman, CM., \& Levy, P.E. (1989). Regulating affect interpersonally: When low esteem leads to greater enhancement. Journal of Personality and Social Psychology, 56, 907-921.

Bern, DJ. (1972). Self-perception theory. In L. Berkowitz (Ed.), Advances in experimental social psychology, Vol. 6. New York: Academic Press.

Brown, J.D. \& Taylor, S.E. (1986). Affect and the processing of personal information: Evidence for mood-activated self-schemata. Journal of Experimental Social Psychology, 22, 436-452.

Cacioppo, J.T. \& Petty, R.E. (1981). Social psychological procedures for cognitive response assessment: The thought-listing technique. In T.V. Merluzzi, C.R. Glass, \& M. Genest (Eds), Cognitive assessment. New York: Guilford Press, pp. 309-341.

Campbell, J.D. (1990). Self-esteem and clarity of the self-concept. Journal of Personality and Social Psychology, 59, 538-549.

Carver, C.S. (1979). A cybernetic model of self-attention processes. Journal of Personality and Social Psychology, 37,1251-1281.

Carver, C.S. \&. Scheier, M.F. (1978). Self-focusing effects of dispositional selfconsciousness, mirror presence, and audience presence. Journal of Personality and Social Psychology, 36, 324-332.

Carver, C.S. \& Schcier, M.F. (1981). Attention and self-regulation: A control theory approach to human behavior. New York: Springer.

Clark, M.S. \& Isen, A.M. (1982). Toward understanding the relationship between feeling states and social behavior. In A. Hastorf \& A. Isen (Eds), Cognitive social psychology. New York: EIscvicr/North-Holland, pp. 73-108.

Csikszentmihalyi, M. \& Figurski, T.J. (1982). Self-awareness and avcrsive experience in everyday life. Journal of Personality, 50,15-28.

Cunningham, M.R. (1988a), Does happiness mean friendliness?: Induced mood and heterosexual self-disclosure. Personality and Social Psychology Bulletin, 14, 283-297.

Cunningham, M.R. (1988b). What do you do when you're happy or blue? Mood, expectancies, and behavioral interest. Motivation and Emotion, 12, 309-331.

Cunningham, M.R., Steinberg, J., \& Grcv, R. (1980). Wanting to and having to help: Separate motivations for positive mood and guilt induced helping. Journal of Personality and Social Psychology, 38,181-192.

Dermer, M., Cohen, S.J., Jacobscn, E., \& Anderson, E.A. (1979). Evaluative judgements of aspects of life as a function of vicarious exposure to hedonic extremes. Journal of Personality and Social Psychology, 37,247-260.

Duval, S. \& Wicklund, R.A. (1972). A theory of objective self-awareness. Orlando, FL: Academic Press.

Fenigstein, A. \& Carver, C.S. (1978). Self-focusing effects of false heartbeat feedback. Journal of Personality and Social Psychology. 36,1241-1250.

Fenigstein, A. \& Levine, M.P. (1984). Self-attention, concept activation, and the causal self, Journal of Experimental Social Psychology, 20, 231-245.

Fenigstein, A., Scheier, M.F., \& Buss, A.H. (1975). Public and private self-consciousness: Assessment and theory. Journal of Consulting and Clinical Psychology, 43,522-527.

Greenberg, J. \& Pyszczynski, T. (1986). Persistent high self-focus after failure and low self- 
focus after success: The depressive self-focusing style. Journal of Personality and Social Psychology, 50, 1039-1044.

Ingram, R.E. (1990). Self-focused attention in clinical disorders: Review and a conceptual model. Psychological Bulletin, 107,156-176.

Ingram, R.E. \& Smith, T.W. (19S4). Depression and internal versus external focus of attention. Cognitive Therapy and Research, 8, 139-152.

Ingram, R.E., Lumry, A., Cruet, D., \& Sieber, W. (1987). Attentional processes in depression disorders. Cognitive Therapy and Research, 11,351-360

Larsen, R.J. \& Cowan, G.S. (1988). Internal focus of attention and depression: A study of daily experience. Motivation and Emotion, 12, 237-249.

Oatley, K. \& Johnson-Laird, P.N. (1987). Towards a cognitive theory of emotions. Cognition and Emotion, 1, 29-50.

Pys2czynski, T- \& Greenberg, J. (1985). Depression and preference for self-focusing stimuli after success and failure. Journal of Personality and Social Psychology, 49,1066-1075.

Pyszczynski, T. \& Greenberg, J. (1986). Evidence for a depressive self-focusing style. Journal of Personality and Social Psychology, 50,95-106.

Pyszczynski, T. \& Greenberg, J. (1987). Self-regulatory perseveration and the depressive self-focusing style: A self-awareness theory of the development and maintenance of depression. Psychological Bulletin, 102, 122-138.

Salovey, P. \& Rodin, J. (1985). Cognitions about the self: Connecting feeling states and social behavior. In P. Shaver (Ed.), Review of personality and social psychology, Vol. 6. Beverly Hills: Sage, pp. 143-166.

Scheier, M.F. \& Carver, C.S. (1988). A model of behavioral self-regulation: Translating intention into action. In L. Berkowitz (Ed.), Advances in Experimental Social Psychology, 27,303-346.

Sedikides, C. (1990). On the covariation of self-focused attention and mood. Unpublished data. University of Wisconsin-Madison.

Sedikides, C. (in press). Changes in the valence of the Self as a function of mood. Review of Personality and Social Psychology, 14.

Smith, T.W. \& Greenberg, J. (1981). Depression and self-focused attention. Motivation and Emotion, 5,323-331.

Smith, T.W., Ingram, R.E., \& Roth, D.L. (1985). Self-focused attention and depression: Self-evaluation, affect, and life stress. Motivation and'Emotion, 9,381-389.

Snyder, C.R. \&Clair, M.S. (1977). Does insecurity breed acceptance? Effects of trait and situational insecurity on acceptance of positive and negative diagnostic feedback. Journal of Consulting and Clinical Psychology, 45, 843-850.

Swann, W.B., Jr. (1985). The self as architect of social reality. In B.R. Schlenker (Ed.), The selfand social life. New York: McGraw-Hill, pp. 100-125.

Taylor, S.E. (1991). Asymmetrical effects of positive and negative events: The mobilizationminimization hypothesis. Psychological Bulletin, 110,67-85.

Thompson, W.C.,Cowan, C.L. \& Roscnhan, D.L. (I960). Focus of attention mediates the impact of negative affect on altruism. Journal of Personality and Social Psychology, 3\$, 291-300.

Wegner, D.M. \& Giuliano, T. (1980). Arousal-induced attention to the self. Journal of Personality and Social Psychology, 38, 719-726.

Wood, J.V., Saltzberg, J.A., \& Goldsamt, L.A. (1990). Does affect induce self-focused attention? Journal of Personality and Social Psychology, 58,899-908.

Wright, J. \& Mischel, W. (1982). Influence of affect on cognitive soda] learning person variables. Journal of Personality and Social Psychology, 43,901-914. 


\section{APPENDIX 1}

\section{Modified Private Self-Consciousness Scale}

Please try to decide on the extent to which each of the following statements is characteristic of yourself right now by placing a number in the blank space preceding each statement. The number should be anywhere from I to 9, according to the following scale:

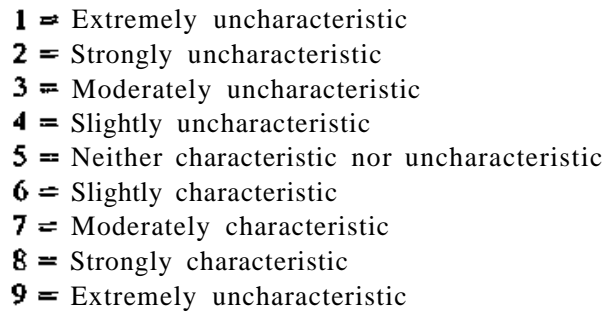

1._ I'm right now trying to figure myself out.

2.— Right now, I'm not very aware of myself.

3._I'm right now reflecting about myself.

4. I'm right now the subject of my own fantasies.

5.—-Right now, I'm not scrutinising myself.

6._Righi now, I'm attentive to my inner feelings.

7._I'm constantly examining my motives.

8. I I right now have the feeling that I'm off somewhere watching myself.

9._ I'm right now alert to changes in my mood.

10._ I'm right now aware of the way my mind works. 